\title{
Will doctors now take a lead on climate change?
}

\author{
Fiona Godlee editor, BMJ
}

Last week was Climate Week in the UK, featuring a host of awareness raising activities across the country. And next Wednesday, 28 March, is NHS Sustainability Day (http:// doc2doc.bmj.com/forums/off-duty_general_nhs-sustainabilityday-of-action). So it seems a good moment to be publishing our Spotlight on climate change. The seven articles have been specially commissioned from among the speakers at last year's high level conference on climate change, hosted by the $B M J$ in partnership with a consortium of other organisations (http:// climatechange.bmj.com).

In case there are any remaining doubters reading the $B M J$, we begin with the science. "No science is ever completely settled," writes Chris Rapley in the first article (doi:10.1136/bmj.e1026). "However, among the tens of thousands of scientists working in the field of climate science worldwide there is almost complete agreement that our climate system is changing, and that human activities are the predominant driving force." Equally firmly agreed upon are the risks to health and life, summarised by Tony McMichael and colleagues_risks that are already realities for many of the world's more vulnerable people (doi:10. 1136/bmj.e1359).

What is less clear is how to reduce or even start to reverse the damage before it's too late. I agree with Robin Stott that a global policy of "contraction and convergence" offers the best hope for our future, addressing climate change and social inequity (doi:10.1136/bmj.e1765). But the political will to achieve this remains elusive. Public engagement and greater efforts to convince politicians will be needed to keep climate change high on the political agenda when the problems of the global economy are so pressing. The question is, can we find a new economics that doesn't rely on environmentally catastrophic growth, and can we find it in time?

In his introduction to the Spotlight Tony Delamothe finds one ray of sunshine: that low carbon economies can improve health (doi:10.1136/bmj.e2207). In their article, Andy Haines and Carlos Dora explain that health professionals are uniquely placed to promote policies that are good for the planet and for people (doi:10.1136/bmj.e1018). Whether doctors are willing to take a lead on this remains to be seen and is the subject of this week's poll on bmj.com.

Elsewhere this week you can read the first in a new occasional series of "Not so stories." Lisa Schwartz and Steven Woloshin have spent much of their professional lives highlighting distortions in the way medical research is reported, whether in journals, drug advertisements, or the media. They've helped demystify medical statistics for lay people, and especially for journalists, who are key to ensuring that research is accurately presented to the public. Knowing that the $B M J$ itself is not immune to the many potential pitfalls in reporting research, we asked them to tell some stories that would educate us and arm $B M J$ readers against being misled. Their first, about the Alzheimer's drug donepezil bodes well for the series but badly for patients (doi:10.1136/bmj.e1086). 